\title{
RUMOS E RUMORES DA PÓSGRADUAÇÃO E DA PESQUISA EM GEOGRAFIA NO BRASIL
}

\begin{abstract}
Resumo
Neste texto são apresentados dados relativos à Pós-graduação em Geografia no Brasil. Num primeiro momento é feito um breve histórico da evolução e distribuição espacial da Pósgraduação em Geografia; um perfil sobre as tendências da geografia após os anos 2000. Associa-se a estes dados um breve levantamento das publicações nas três revistas mais representativas da região Sul do Brasil, objetivando, por fim, caracterizar, brevemente, a produção geográfica no sul do país.
\end{abstract}

Palavras-chave: Geografia; Pós-Graduação, Produtividade e Produção.
Dirce Maria Antunes Suertegaray Prof ${ }^{a}$ Titular Departamento de Geografia UFRGS suerte.ez@terra.com.br

\begin{abstract}
This paper presents data on postgraduate education in geography, in Brazil. First, a brief history of the evolution and spatial distribution of geography postgraduate education is presented; a profile of geography trends after the year 2000. A short survey of articles published in the three most representative journals of the South Region of Brazil is associated to such data, aiming at a brief characterization of the geographic production in the south of the country.
\end{abstract}

Key Words: Geography; (post)graduate education, productivity and production.

\section{$0 \bigcirc 0$}

\section{INTRODUÇÃO}

Neste texto o objetivo é apresentar alguns dados relativos à Pós-graduação em Geografia no Brasil. Num primeiro momento é feito um breve histórico da evolução e distribuição espacial da Pós-graduação em Geografia. Além deste breve histórico é também intenção deste texto apresentar, a partir dos dados da produção dos programas de Pós-graduação no Brasil, um perfil sobre as tendências da geografia após os anos 2000. Esta tendência é indicada pelo que se revela na produção acadêmica vinculada a Pós-graduação, portanto, não corresponde ao universo da produção neste campo do conhecimento em território brasileiro. Associa-se a estes dados um breve levantamento das publicações nas três revistas mais representativas da região Sul, a revista Ra'ega da UFPR, a Geosul da UFSC e o Boletim Gaúcho de Geografia da AGB - Porto Alegre. Trabalho elaborado no mesmo período com o objetivo de caracterizar brevemente a produção no sul do país.

\section{UM BREVE HISTÓRICO}

Extraímos esse texto, um breve histórico, do relatório CAPES(2005), entretanto o leitor pode encontrar diferentes visões e mapeamentos feitos sobre a Pós-graduação em Geografia no Brasil em: Gerardi (2003), Suertegaray(2003,) Duarte(2003), Carlos (2003).

“Os primeiros cursos de pós-graduação" em Geografia a integrarem o Sistema Nacional de PósGraduação foram os de Geografia Humana e de Geografia Física da Universidade de São Paulo, criados em 1971, seguidos do Programa de Pós-Graduação em Geografia da UFRJ, implantado em 1972. A partir destes programas pioneiros, a área experimentou um lento crescimento; ao final da década de 1970 eram 5 e na de 1980 eram oito os programas implantados, cinco deles na região Sudeste, dois no Nordeste e um na região Sul. 
O número de cursos expandiu-se na segunda metade da década de 1990, quando se chegou a 19 cursos (Fig. 1 e 2). Esta expansão não se arrefeceu, pois neste início de década de 2000 é expressivo o crescimento. Em 2005, em termos totais a área contava com 32 cursos de mestrado e 15 de doutorado. Estes dados indicam que área tende manter a expansão e, para o futuro próximo prevê-se um incremento de novos cursos de doutorado e uma tendência à interiorização dos cursos de mestrado. Além desta expansão em relação à solicitação de novos mestrados, a demanda cresce a partir das regiões Norte e Nordeste, que ainda apresentam carência de cursos de pós-graduação em Geografia.

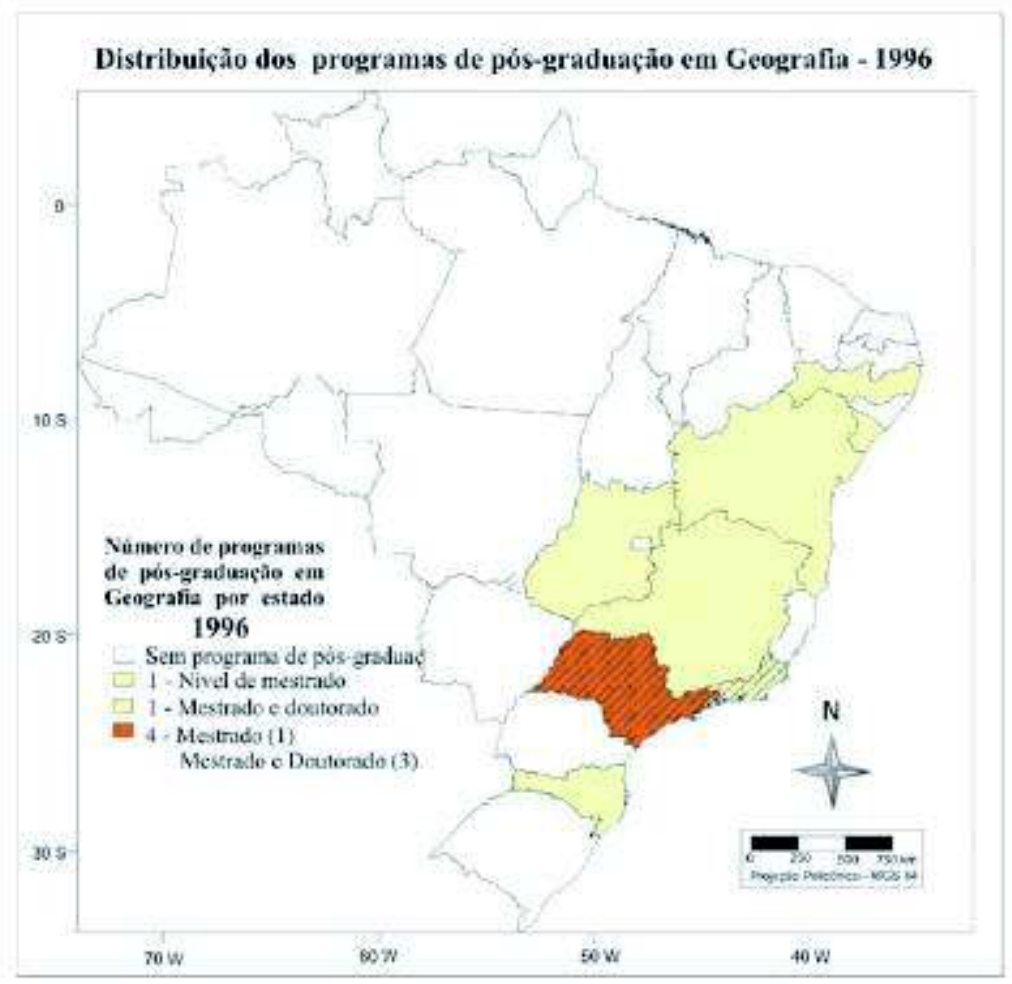

Fig 1. 
Fig 2.

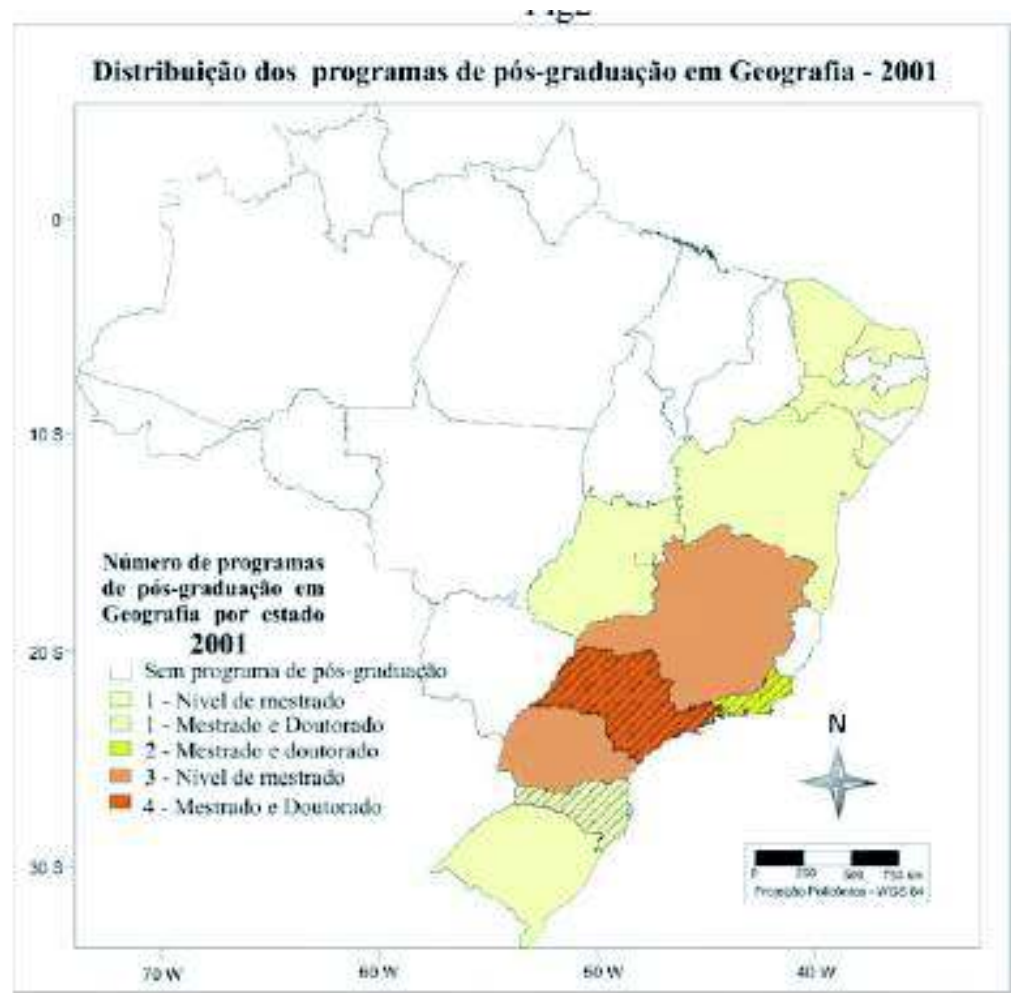

Elaborado por Clódis de O. Andrades Filho, bolsista PIBIC/CNPq/UFRGS

A distribuição regional dos cursos de mestrados apresenta-se da seguinte forma: Sudeste 38\% sendo que o estado de São Paulo ficou com19\%; Sul 21\% sendo que o estado do Paraná ficou com 12\%; Centro-Oeste 12\%; Nordeste 22\%; e Norte 6\%. Quanto ao doutorado, sua distribuição apresentou-se da seguinte maneira: Sudeste 67\% sendo que o estado de São Paulo ficou com 33\%; Sul 20\%; Nordeste 13\%; as regiões Centro-Oeste e Norte não possuem nenhum curso de doutorado. )".Relatório de área/ CAPES 2005.(gráfico.1 e fig. 3) 
Gráfico 3 - BRASIL - Evolução da Pós-Graduação em GEOGRAFIA - 1971/2005 - Cursos novos

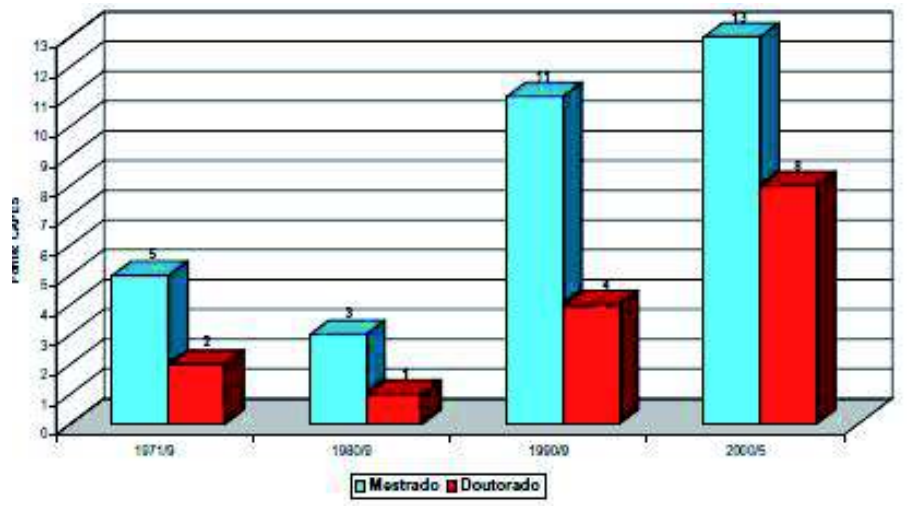

Fonte: Relatório da área de Geografia CAPES, 2005.

Mais recentemente a área de geografia ampliou o número de cursos. Ainda em 2006 foram aprovados os seguintes cursos, doutorado na UFGO, mestrado na UFGD, UFAM, UNIOESTE e PUC/RJ. Em 2007 a área aprovou mais um curso de mestrado - UFES. Atualmente a área conta com um total de 38 cursos de Pós-graduação.

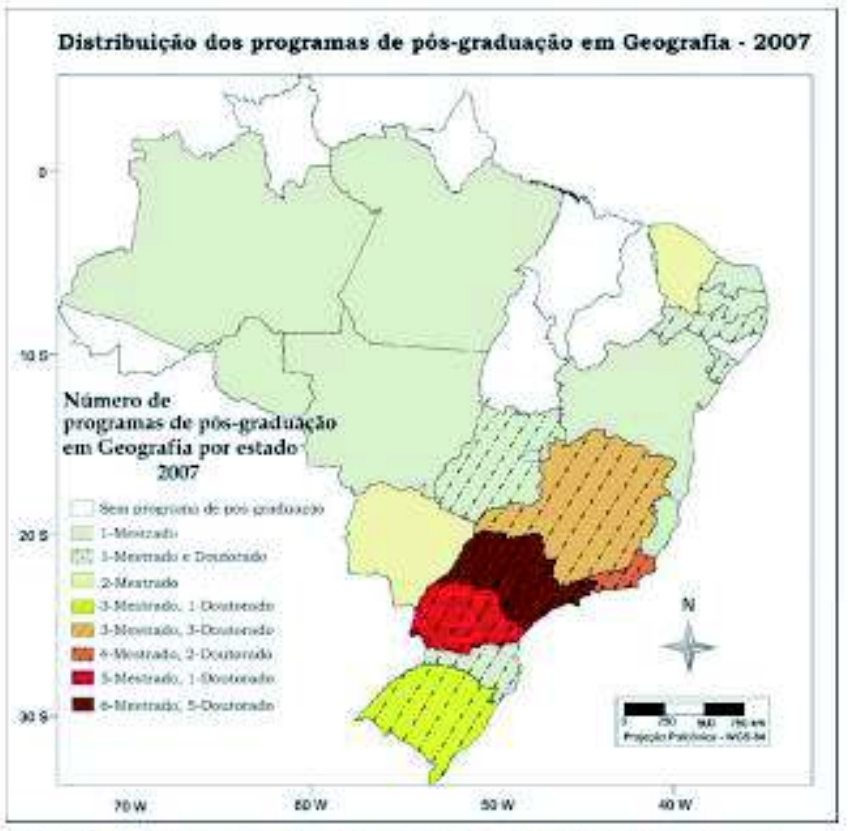

Elaborado por Clódis de O. Andrades Filho, bolsista PIBIC CNPqUFRGS

Fig 3. 


\section{O PERFIL DA PÓS-GRADUAÇÃO}

A distribuição da Pós-graduação em Geografia no Brasil, ainda que apresente significativa dispersão apresenta grandes lacunas, em termos estaduais, na região Norte e Nordeste. Com a aprovação, recentemente, do curso de mestrado na UFES o espaço territorial na escala estadual, na região Sudeste, se completa. Entretanto, esta distribuição se tomarmos o número de doutorados ainda se apresenta de forma concentrada. Para o conjunto da Pós-graduação a área de Geografia tem 16 cursos de doutorado. Destes a grande maioria está concentrada na Região Sudeste - são 10 cursos concentrados em três estados, 5 em São Paulo, 3 em Minas Gerais e 2 no Rio de Janeiro. A região Nordeste formada por um conjunto de 9 estados abriga 2 cursos de doutorado e a Região Centro-oeste um curso. A região sul conta com um curso de doutorado em cada um e seus estados, configurando no conjunto 3 doutorados.

O perfil destes cursos e programas da mesma forma apresenta-se diferenciado.

De acordo com as notas atribuídas a esses cursos e programas a distribuição atual expressa-se nos seguintes dados: dos 38 cursos aprovados 20 cursos e ou programas tem nota 3, 9 cursos e ou programas nota 4. Programas com nota cinco (5) são em número de cinco e com nota 6 são em número de três. Destes dois estão em São Paulo e um no Rio de Janeiro.

No que se refere às áreas de concentração verifica-se uma tendência à análise no campo da Geografia Humana. Sendo que são os programas mais tradicionais, do ponto de vista de sua história de construção que detém a formação, mais significativa, na área denominada Geografia Física.

No que se refere à produção e os veículos de divulgação da pesquisa geográfica cabe dizer que a área valoriza três veículos na difusão do conhecimento geográfico, os periódicos, os anais de eventos e os livros. Estes são significativamente importantes para a área das humanidades e se revelam fundamentais na divulgação do conhecimento geográfico. A cada ano a produção se amplia. Os livros, os periódicos e os anais sendo instrumentos de divulgação do conhecimento, para a agência avaliadora necessitam ser qualificados. A grande dificuldade é qualificar exatamente os livros. Estes instrumentos de difusão também se revelam diferenciados para o conjunto dos programas. Há aqueles que privilegiam as publicações em periódicos, outros em anais de eventos e outros priorizam a publicação em livros Destaca-se, ainda,a produção mais atual de revistas eletrônicas. Esta ampliação de revistas nessa modalidade poderá indicar para um futuro em curto prazo uma mudança do perfil de difusão do conhecimento geográfico. Há, nessa produção uma possibilidade de canalização do produto geográfico para a divulgação em forma de periódicos.

Uma outra característica desse perfil é a ampliação da constituição de redes de pesquisa e ou ensino entre os programas de diferentes regiões. Essas parcerias podem ser formais como no caso de elaboração de projetos comuns agenciados pela CAPES, ou parcerias mais espontâneas elaboradas através de reuniões de discussão e temas de pesquisa específica. Da mesma forma em relação à inserção e ao intercâmbio internacional. Ampliam-se os convênios, os estágios Pós-doutorais no estrangeiro e a construção de redes de pesquisadores em Geografia, destacando-se em muitos casos parcerias com a América Latina. Incluindo aqui parcerias na formação profissional através do apoio a cursos de mestrado em outros países latinos.

Mais recentemente, a avaliação a CAPES incluiu, em particular como quesito para avaliação de cursos de excelência os critérios denominados: nucleação e transparência. Em relação à nucleação mais especificamente em relação ao item - consolidação e liderança nacional do programa como formador de recursos humanos para a pesquisa e a pós-graduação avalia-se como altamente promissor o desempenho de alguns cursos, particularmente, aqueles já historicamente consolidados. A análise do perfil dos docentes de muitos dos novos cursos revelam o processo de formação acadêmica e geração de novos núcleos 
de pesquisa e constituição de cursos de Pósgraduação, por parte desses cursos. Por vezes um número significativo de docentes de novos cursos tem sua formação em um único programa, desses aos quais nos referimos como consolidados, a exemplo da Geografia da USP, UFRJ, UNESP/RC e UNESP/PP.

Este deslocamento, para muito desses alunos se faz motivado pela escolha de grupos de pesquisa $\mathrm{e}$ temas do corpo docente de diferentes programas.

Um outro item que vem sendo contemplado é - Inserção e impacto regional e (ou) nacional do programa; integração e solidariedade com outros programas com vistas ao desenvolvimento da pesquisa e da pós-graduação e visibilidade ou transparência dada à sua atuação. Cursos consolidados e cursos mais novos seguem essa direção na medida em que se visualiza uma mobilidade estudantil significativa. Onde, alunos do Norte buscam cursos em regiões Centro e do Sul e alunos do Sul se dirigem ao Sudeste e ou Nordeste, Centro-oeste. Melhor dizendo há um deslocamento se inicia em diferentes direções. Este deslocamento, para muito desses alunos se faz motivado pela escolha de grupos de pesquisa e temas do corpo docente de diferentes programas. O modelo anterior e mobilidade apenas para o centro do país assumem outros contornos.

Em relação ao perfil cabe registrar algo sobre a produção científica. Para tanto me valho do trabalho de Silva e Dantas (2005). Em suas considerações finais os autores revelam a partir da análise feita, que na avaliação dos cursos e programas "torna-se impraticável adotar postura reducionista reinante e crédula de ser o conceito dos cursos diretamente relacionado à produção docente em seu estado bruto, sendo os demais quesitos meramente ilustrativos" (p.37).

E prosseguem a suas considerações informando que "a maioria dos programas mais antigos, que dispôs de melhores conceitos, não se insere no mesmo patamar de produtividade docente dos programas e cursos novos e em fase de consolidação".

Diante disto questionam a ímpeto produtivista que se instala em diversos programas. Esta análise é reveladora, de um lado, do produtivismo que se expande pela área e, de outro, da necessidade sim de produzir de forma coerente e através dos veículos reconhecidos pela área. O tema é controvertido mas revelador do perfil que se deseja apontar.

\section{TENDÊNCIAS DA PESQUISA EM GEOGRAFIA (teses e dissertações)}

A explicação dos procedimentos adotados bem como as conclusões aqui apresentadas não é inédita, foram originalmente publicadas em Suertegaray (2005).

Para fazer esta análise, avaliou-se, a partir da produção de teses e dissertações dos 29 programas distribuídos em território nacional, alguns elementos que podem indicar, através do título do trabalho, atualidade e tendências. Para tanto, levantei duas dimensões que norteiam minhas preocupações: a escala de análise e os subcampos da Geografia. Considerando a escala, classifiquei os trabalhos nas escalas local, regional, nacional e abrangência internacional. A definição dos campos temáticos (sub-unidades da Geografia) não foi feita a priori, resultou da análise do conjunto de dissertações e teses, portanto, constitui elemento de indicação de tendência. Observei, para o conjunto dos dados, temas relativos à Geografia Física, Geografia Humana, Ambiente, Educação e Geografia, Teoria e Método em Geografia.

Os dados aqui apresentados são referentes a um período de 4 (quatro) anos (2000/2003). O limite em 2003 ocorre devido à disponibilidade dos dados no sítio da CAPES, de onde extraímos estas informações.

Os cursos analisados são, em número, 29. Deste conjunto, são extraídos os cursos novos cujos dados de dissertações defendidas não estão, ainda, registrados. Esta análise, mais detalhadamente apresentada em Suertegaray (2005) registrou as seguintes tendências: 


\section{Indicações de Algumas Tendências}

As tendências observadas ao longo deste processo de análise de teses e dissertações são registradas, aqui de forma tópica. São elas:

- Produção geográfica da maioria dos programas, basicamente dividida entre Geografia Humana e Ambiental, aparecendo de forma muito reduzida à produção na Geografia Física. Os dados levantados me permitem dizer que, na atualidade, existe uma forte tendência aos estudos ambientais e, conseqüentemente, um deslocamento dos estudos compreendidos como Geografia Física para esta área.

- Os temas abordados no conjunto da produção brasileira no contexto ambiental estão associados a estudos de impactos ambientais, diagnósticos, zoneamentos, monitoramentos, além dos estudos de risco ambiental. Em geral, esses estudos estão assentados sob o espaço urbano, bacias hidrográficas, parques e reservas nacionais.

- Os dados revelem uma predominância do ensino/pesquisa no campo das humanidades (Geografia Humana). Os dados absolutos sobre o conjunto da produção dos cursos de Pós-graduação nos permitem concluir sobre esta tendência. Neste período a produção, em Geografia Humana, foi de 740 trabalhos (entre teses e dissertações).

Na Geografia Física a produção foi de 215 teses e dissertações, um número menor às teses e dissertações produzidas sobre temas ambientais (310).

- Na perspectiva do ensino, a produção em números ainda é pequena, 67 produtos em 4 anos. Esta produção está representada em 14 dos 23 cursos com registro de produção. Destes, oito (8) não registram teses e dissertações sobre ensino em Geografia.

Em relação à escala de análise cabe destacar:

- A análise local constitui uma tendência na Geografia atual. Não necessariamente a indicação de um espaço local pode circunscrever a análise ao local. O que aqui parece ser importante registrar é o direcionamento do tema à explicação local. Esta é uma tendência que se configura pela demanda de conhecimento e, por vezes, gestão de espaços como bairros, áreas centrais, assentamentos rurais, bacias hidrográficas, parques e reservas ou territorialidades urbanas dos mais diferentes matizes.

- Na escala nacional da mesma forma. Carecemos de entendimento do Brasil na sua abrangência. Constitui para nós um grande desafio quando é solicitado pensar uma temática como, por exemplo, o desmatamento em escala nacional, entre outros temas. A Geografia do Brasil como resultante da temática geográfica produzida em escala nacional está para ser reconstruída.

- Praticamente não há registros no período de estudos em escala global. Pequenas inserções em temas internacionais são observadas, particularmente nas grandes universidades.

\section{TENDÊNCIAS EM PERIÓDICOS REGIONAIS}

Num outro momento foi elaborado um levantamento da produção divulgada em periódicos da região Sul. Optou-se pelos periódicos com vínculo direto aos programas de Pós-graduação (revistas RA'E GA e Geosul) e ou estreita relação com a produção do programa, a exemplo do Boletim Gaúcho de Geografia (BGG).

Da mesma forma que a análise anterior à análise considerou áreas temáticas e escalas de análise. A tabela 1 apresenta os dados levantados. Nessa tabela fica evidente a dominância dos estudos de Geografia Humana em relação aos de Geografia Física e Ambiental para as três revistas analisadas. Em relação às 
publicações da Geografia Física, observou-se nesse período um maior número de artigos divulgados na revista $R A$ 'EGA.

Nestas, o maior número de publicações diz respeito a Teoria e Método em Geografia, isto não significa dizer que isto revela uma tendência geral nos estudos geográficos, para os estudos teóricos, possivelmente, demonstre uma retomada da discussão neste nível. É evidente a presença de publicações no campo ambiental nas revistas RA'EGA e Geosul, enquanto o BGG/PA veiculou trabalhos dominantemente na Temática Regional e Urbana.

Em relação à escala de análise são dominantes os estudos em escala local, comparativamente aos em escala regional e nacional. Embora o número de publicações entre as escalas não seja tão desigual, em particular a local e a regional, é observável o reduzido número de trabalhos em escala nacional.

Tabela 1

Publicaçòes em Geografia: veiculos dos programas de Pós-graduaçào e Boletins Locais - Região Sul. Classificaçào por tema (2004)

\begin{tabular}{|c|c|c|c|c|c|c|c|c|}
\hline & $\begin{array}{c}\text { Teoria/Método } \\
\text { e Ensino }\end{array}$ & Regional & Urbano & Agrário & $\begin{array}{l}\text { Político } \\
\text { Econômico }\end{array}$ & Ambiental & $\begin{array}{l}\text { Geografia } \\
\text { Social e } \\
\text { Cultural }\end{array}$ & $\begin{array}{l}\text { Outros } \\
\text { setores da } \\
\text { Geografia } \\
\text { Fisica }\end{array}$ \\
\hline GEOSUL & 35 & 6 & 2 & 3 & 10 & 10 & 2 & 6 \\
\hline RAE'GA & 21 & 3 & 3 & 1 & 3 & 11 & - & 5 \\
\hline BGG & $\begin{array}{r}38 \\
13(\mathrm{E}) \\
\end{array}$ & 6 & 6 & 3 & 5 & 7 & 1 & 2 \\
\hline TOTAL & 94 & 15 & 11 & 7 & 18 & 28 & 3 & 13 \\
\hline
\end{tabular}

Tabela 2

Escala da análise dos trabalhos divulgados em revistas de Geografia - Regiào Sul (2004)

\begin{tabular}{l|llll}
\hline & Local & Regional & Nacional & Global \\
\hline GEOSUL & 16 & 18 & 6 & - \\
\cline { 1 - 4 } RAE'GA & 13 & 10 & 4 & - \\
\cline { 1 - 3 } & 15 & 7 & 2 & - \\
\hline TOTAL & $\mathbf{4 4}$ & $\mathbf{3 5}$ & $\mathbf{1 2}$ & \\
\hline
\end{tabular}

\section{CONSIDERAÇÕES FINAIS}

Na revista da ANPEGE, Mendonça (2005) promove alguns questionamentos sobre a Pós-graduação em Geografia no Brasil que penso, a título de prestação de contas desses três anos frente à representação da área na CAPES, que devam ser comentados dado a relevância de tal questionamento.

A primeira consideração do autor acima referido diz respeito à distribuição - concentração geográfica dos Cursos e Programas. Nesse sentido os dados expostos expressam a política adotada pela área associada à política da CAPES de ampliação da malha da Pós-graduação em especial para as áreas que apresentam essa lacuna. 
Uma segunda consideração diz respeito à Amazônia que para o autor, permanecendo os critérios até então sugeridos, a região continuaria com seu conhecimento vinculado aos pesquisadores estrangeiros. A preocupação de Mendonça foi absorvida pela CAPES quando promoveu a expansão de Cursos através do programa Avança Amazônia (criado nesse atual triênio). A Geografia nessa região conta atualmente com três cursos de mestrado, a despeito das criticas advindas por parte de alguns grupos da Geografia sobre a disseminação pouco criteriosa de cursos. A terceira colocação diz respeito à pesquisa e o autor nos remete a pensar sobre a necessidade de "uma formação voltada ao Brasil, que o tome na escala da nação brasileira". (MENDONÇA, 2005).

Do ponto e vista da produção a análise apresentada neste texto revela essa lacuna.

Esta análise não registra o conjunto da produção nos curso de mestrado e programas de Pós-graduação em geografia na sua totalidade, do ponto de vista espacial ou temporal. Entretanto, permite observar algumas tendências. No período analisado observou-se o domínio da produção geográfica em Geografia Humana e um deslocamento dos estudos de Geografia Física para análise ambiental.

Em relação às escalas de análise uma predominância de estudos em escala local e grandes lacunas de análises na escala Regional e Nacional.

Embora parciais e descritivos considera-se que estes dados expressam uma tendência. Daí a pertinência de seus registros. Outros trabalhos de cunho analítico poderão a partir deles, serem elaborados. Constituiu este texto uma tentativa de apresentar os rumos da Pós-graduação em Geografia no Brasil e, em alguns momentos, explicita ou implicitamente registrar os rumores que esta trajetória revela.

\section{REFERÊNCIAS BIBLIOGRÁFICAS}

CARLOS, A. F.A. Questões para a construção de uma política de pós-graduação em geografia. Revista da ANPEGE ano $1, \mathrm{n}^{\circ} 1$ Curitiba, PR 2003.

DUARTE, G..M. A pesquisa e a Pós-graduação em Geografia no Brasil-os dez anos da ANPEGE. . Revista da ANPEGE ano 1, nº1Curitiba, PR 2003.

GERARDI, L.H.de O. ANPEGE: O resgate de uma história. Revista da ANPEGE ano 1, nº1Curitiba, PR 2003.

MENDONÇA, F. Temas, Tendências e desafios da Geografia na Pós-graduação Brasileira. Revista da ANPEGE, ano $2 n^{\circ} 2$. ANPEGE, Fortaleza, CE. 2005

SILVA. J. B.da e DANTAS. E.W. C.A pós-graduação em Geografia no Brasil: uma contribuição à política de avaliação. Revista da ANPEGE, nº2. ANPEGE,São Paulo. 2005

SUERTEGARAY, D.M.A. A expansão da pós-graduação em Geografia no Brasil e a ANPEGE. Revista da ANPEGE ano $1, \mathrm{n}^{\circ} 1$ Curitiba, PR 2003.

SUERTEGARAY, D. M. A.. O atual e as tendências do ensino e da pesquisa em geografia no Brasil. Revista do Departamento de Geografia (USP), São Paulo,v. 16, p. 38-45, 2005.

WWW Capes.gov.br.

Recebido em maio de 2007

Aceito em agosto de 2007 